\title{
Instruments to assess children's language and speech translated and adapted into Brazilian Portuguese: an integrative literature review
}

\author{
Letícia Cristina Silva1 \\ https://orcid.org/0000-0002-7868-193X \\ Dionísia Aparecida Cusin Lamônica' ${ }^{1}$ \\ https://orcid.org/0000-0002-9381-0680 \\ Simone Rocha de Vasconcellos Hage ${ }^{1}$ \\ https://orcid.org/0000-0003-4790-6937
} 1 Universidade de São Paulo, Faculdade de
Odontologia de Bauru - FOB/USP, Bauru, São Paulo, Brasil

Research support source: CAPES

Conflict of interests: Nonexistent

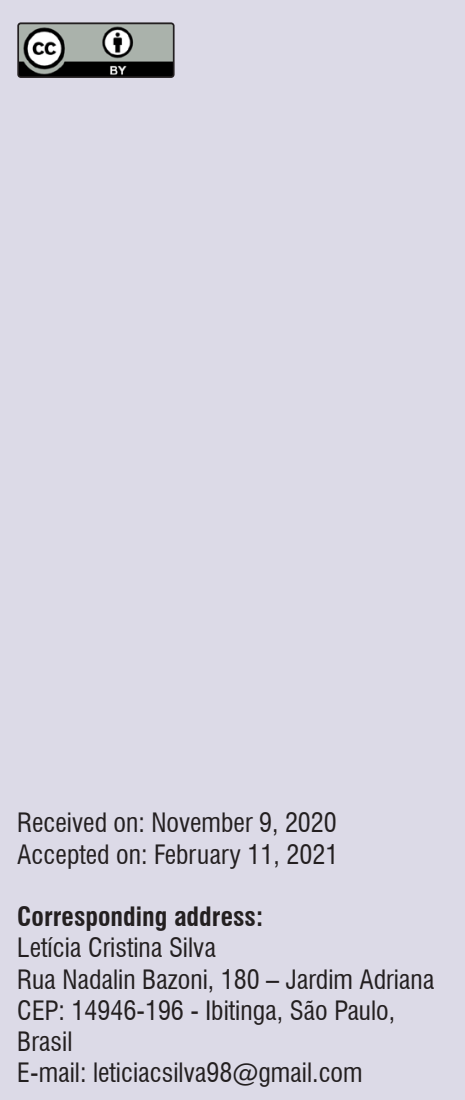

\section{ABSTRACT}

Purpose: to analyze the content and translation guidelines of instruments meant to assess language, speech sound production, and communicative skills of children, adapted to Brazilian Portuguese.

Methods: a search was conducted in national and international databases to select articles on the assessment of language, speech, and communicative skills in children, considering the descriptors "translation", "adaptation", "cultural adaptation", "crosscultural adaptation", "language", "speech", and "pragmatic". The search was conducted in the SciELO, Virtual Health Library, PubMed/MEDLINE, and Latin American and Caribbean Health Sciences Literature.

Results: eight assessment instruments compatible with the inclusion criteria were found.

Conclusion: of the instruments found, four approached specific investigations, such as syntax, narrative, pragmatic skills, and speech sound organization, while the other four had a more encompassing profile, verifying form, content, and/or use (pragmatics). Concerning the guidelines, the most recurrent stages between the translation proposals were translation, conciliation of the previous stage or synthesis version, backtranslation, reviewing committee, pretest, and final version. The conceptual, item and operational equivalences were frequently cited for verification.

Keywords: Translating; Adaptation; Language; Speech 


\section{INTRODUCTION}

An assessment is an "appreciation, judgment, or concept formed about something"1 - a task that demands responsibility and pondering. According to the American Speech-Language-Hearing Association $(\mathrm{ASHA})^{2}$, the assessment, description, and interpretation of the human capacity to communicate require the integration of various pieces of information. The ASHA standards of best practices for speech-languagehearing therapists indicate that the assessment must include standardized measures of specific aspects of speech, verbal and nonverbal language, communication, and swallowing function, considering cultural adaptation and validity criteria. These measures can be standardized tests, verbal language sample analysis, systematic and contextual observations of the communicative behavior, questionnaires filled out by relatives, or even based on the school curriculum. Regardless of the type of procedure, it is essential to consider the cultural aspects and the language spoken in the social surroundings.

Although countries as the United States have a broad range of speech-language-hearing assessment instrument, listing more than 100 speech-language tests in the 2006 edition of the Directory of SpeechLanguage Pathology Assessment Instruments published by $\mathrm{ASHA}^{2}$, there is a different scenario in Brazil, where few formal instruments are available in Brazilian Portuguese indicated for assessment and diagnosis ${ }^{3-7}$. Translating assessment instruments from other languages has been one of the means to supply the need not only regarding diagnosis but also the definition of intervention plans ${ }^{7,8}$. Translating procedures that are already being used in other languages has an additional scientific gain, as it enables data on communication disorders and their specificities to be observed in different languages ${ }^{4}$. Thus, various populations are compared, and information is exchanged without the bias of cultural and linguistic barriers.

However, the translation process must be rigorous, supported by well-established guidelines that ensure valid and reliable interpretations ${ }^{6,9}$. The translated version must be as equivalent as possible to the original instrument in its various levels, such as the semantic, idiomatic, experiential, and conceptual ones $^{10}$. The semantic verification, although essential to the translating process, is only part of the crosscultural adaptation process - which combines literal translation from one language into the other and content adaptation to the lifestyle and cultural context of the population to whom the translated version is intended ${ }^{10,11}$. The cross-cultural adaptation is essential because using an instrument that has not been properly adapted to the culture of the country where the language is spoken may compromise the validity of the assessments made with $\mathrm{it}^{12}$. Adapting instruments that assess linguistic aspects is even more critical, as some communication disorders can manifest differently from one language to the other ${ }^{2}$.

In the field of translation, groups of researchers have suggested guidelines to be followed for the standardized translation and cross-cultural adaptation of instruments, to avoid inadequacies in meaning. What language and speech sound assessment instruments have been translated and adapted into Brazilian Portuguese, and what translation guidelines were mostly used? That is the question for this research. Hence, this study aimed to analyze the content and guidelines used to translate and adapt into Brazilian Portuguese instruments that assess language, speech sounds, and communicative skills in children.

\section{METHODS}

National and international databases were searched to select articles approaching the assessment of language, speech, and communicative skills in children. The search was carried out in the SciELO, Virtual Health Library (VHL), PubMed/MEDLINE, and Latin American and Caribbean Health Sciences Literature (LILACS, IBECS, and ADOLEC).

The descriptors used in the first stage of the search were "Translation" AND "Adaptation" OR "Cultural adaptation" OR "Cross-cultural adaptation" AND "Language". In the second stage, the following were used: "Translation" AND "Adaptation" OR "Cultural adaptation" OR "Cross-cultural adaptation" AND "Speech". And in the third stage, they were "Translation" AND "Adaptation" OR "Cultural adaptation" OR "Crosscultural adaptation" AND "Pragmatic".

The exclusion criteria were the following: (1) repeated articles, either written in more than one language or present in more than one database; (2) articles that did not approach the translation of instruments meant to assess language, speech sounds, or communicative skills; (3) articles on instruments whose target audience was not children under 10 years old; (4) instruments translated to languages other than Brazilian Portuguese; and (5) articles not describing the instrument or the translation process. The research 
considered open-access articles written in the last 15 years (between 2005 and 2020), although none of the articles was dismissed due to either of these factors. Figure 1 shows the results of the first stage, Figures 2 and 3 show the results of the second and third stages, respectively, and Figure 4 shows the stage in which the articles were selected to be used in the research. Most of the articles found were repeated in all the databases and were thus excluded based on the first exclusion criterion, whereas only one of the articles was not eligible for the study because it did not present the translation process or the guideline it followed.

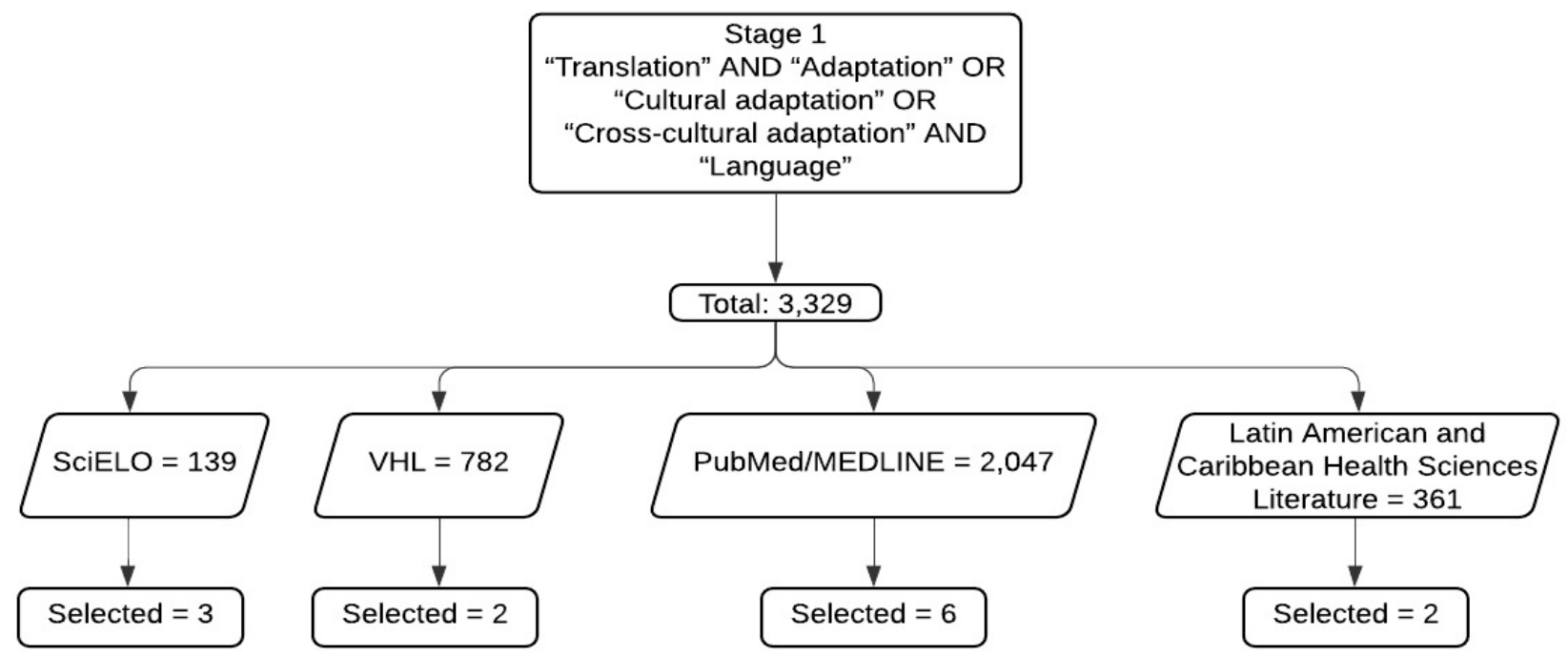

Figure 1. Results found in the first stage of database search

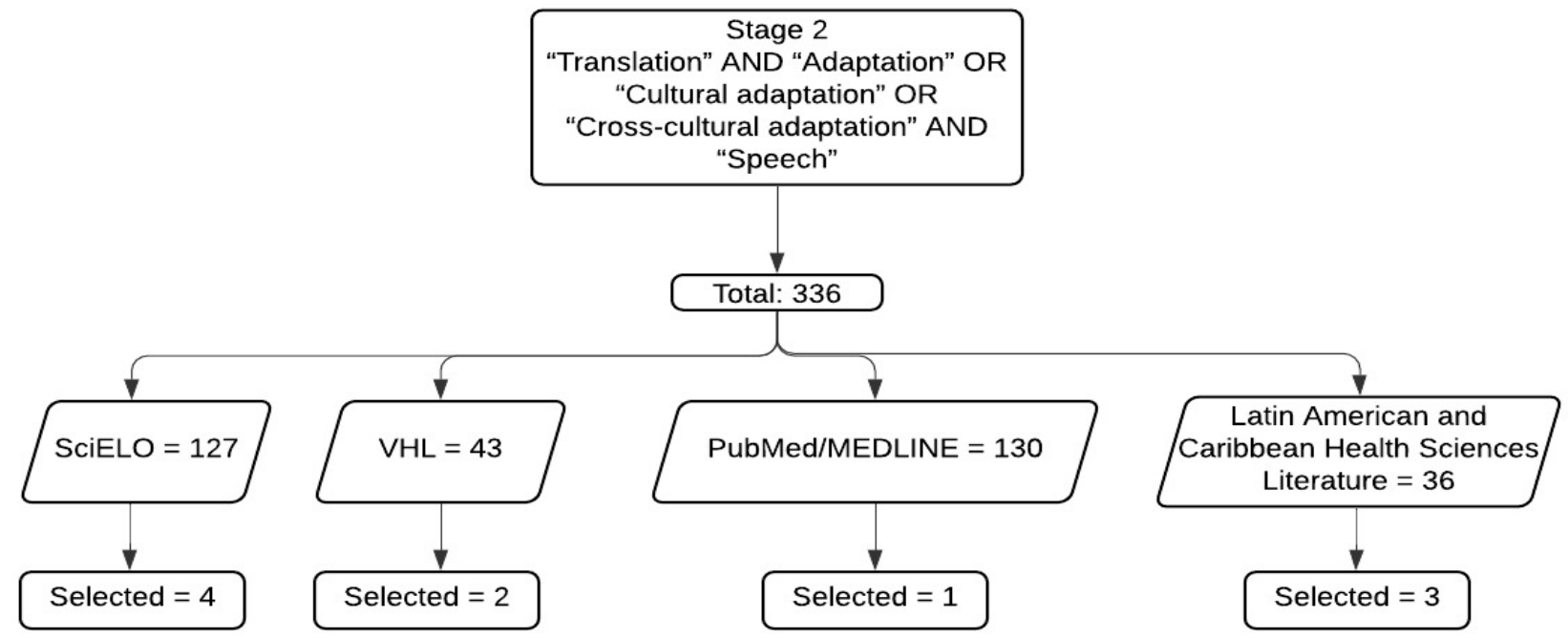

Figure 2. Results found in the second stage of database search 


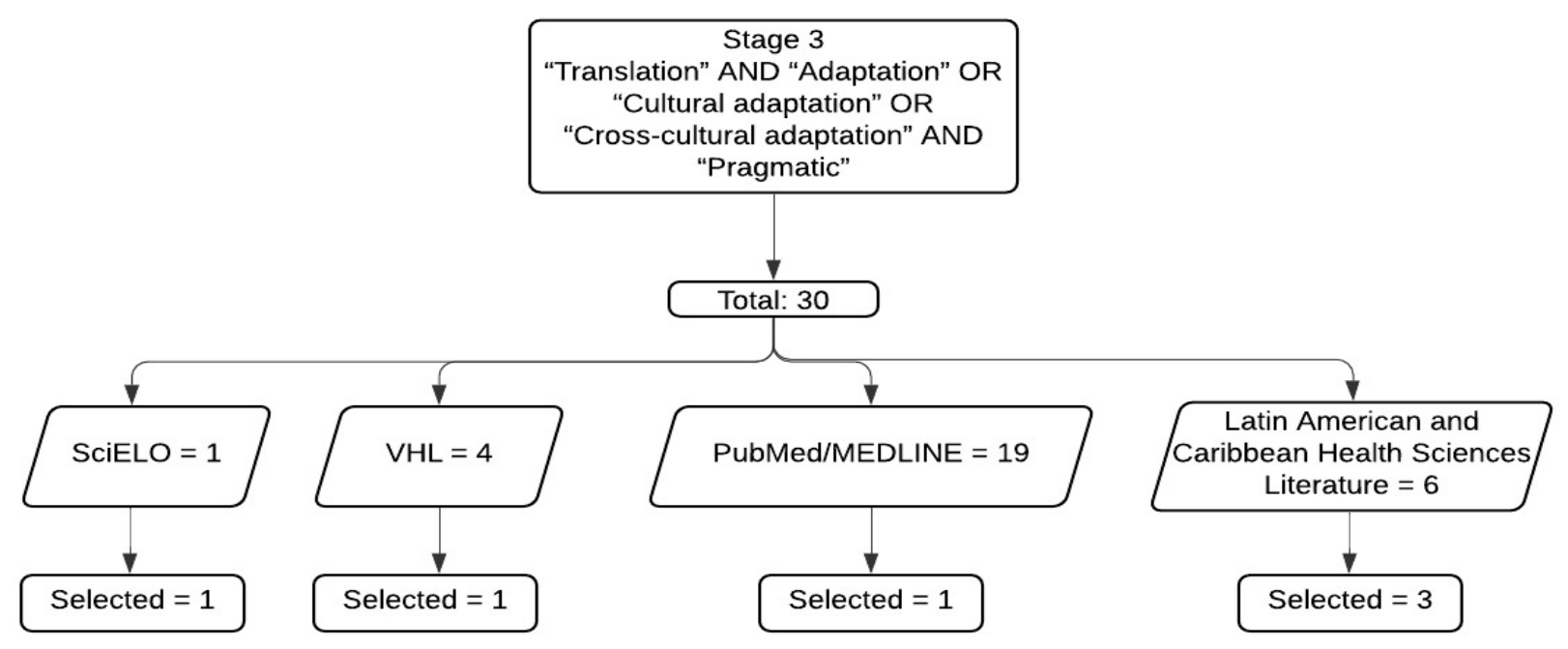

Figure 3. Results found in the third stage of database search

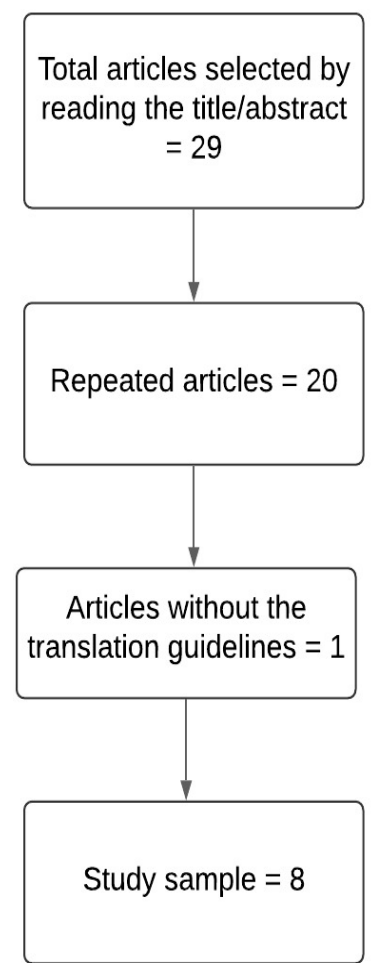

Figure 4. Flowchart of selected and dismissed articles

\section{LITERATURE REVIEW}

Altogether, eight instruments were found which had been translated and cross-culturally adapted into Brazilian Portuguese and met the inclusion criteria. The final list is as follows, as demonstrated in Chart 1.

Health professionals have long been concerned with using standardized assessment instruments that can be employed in various countries with various languages, as long as they are culturally adapted. In clinical practice, such instruments make it possible to document clinical care and are essential to diagnose and verify the effectiveness of the treatment. In Brazil, regarding language and speech sound assessment instruments, the tendency in the last decade has been to adapt procedures already standardized and tested in other countries, especially the United States. This review found eight instruments that met the inclusion criteria, of which seven had been published in the last six years.

Concerning content analysis, most of the translated and adapted instruments evaluate oral language based on Bloom's model ${ }^{35}$, which defines language as a code with which ideas are expressed in a conventional system of arbitrary signs to communicate. In this context, language development is verified in terms of its form (phonology, syntax, and morphology), content (semantics), and use (pragmatics).

The Test of Early Language Development (TELD$3)^{13}$ aims to early identify changes in language development. The instrument was developed to assess language comprehension and production of preschoolers and of children beginning to learn to read and write. It verifies receptive and expressive language with 37 and 39 items, respectively, investigating semantic, syntactic, and morphological aspects of language as a whole, not providing specific data of each one of the aspects. Based on the raw scores, the child's linguistic age is established.

With the same profile, the Preschool Language Instrument, $2^{\text {nd }}$ edition (PLAI-2) ${ }^{17}$ evaluates the language of preschool children up to 5 years old, furnishing a 
Chart 1. Description of the instruments, authors, translators, age group, and guidelines used

\begin{tabular}{|c|c|c|c|c|c|}
\hline Instrument & $\begin{array}{l}\text { Authors } \\
\text { (year) }\end{array}$ & $\begin{array}{c}\text { Translators } \\
\text { (year) }\end{array}$ & Age group & What is assessed & Translation guidelines \\
\hline TELD - 3 & $\begin{array}{l}\text { Hresko, Reid, } \\
\text { and Hammill'13}\end{array}$ & $\begin{array}{l}\text { Giusti and Befi- } \\
\text { Lopes }^{14}\end{array}$ & 2 to 7 years & $\begin{array}{l}\text { Receptive and expressive } \\
\text { language regarding } \\
\text { structure and content }\end{array}$ & $\begin{array}{l}\text { Guillemin, Bombardier, and } \\
\text { Beaton }{ }^{15} \text {; Herdman, Fox- } \\
\text { Rushby, and Badia }{ }^{16}\end{array}$ \\
\hline $\begin{array}{l}\text { Preschool Language } \\
\text { Instrument (PLAl-2) }\end{array}$ & $\begin{array}{c}\text { Blank, Rose, and } \\
\text { Berlin }^{17}\end{array}$ & $\begin{array}{l}\text { Lindau, Rossi, } \\
\text { and Giachetti }{ }^{18}\end{array}$ & 3 to 5 years & $\begin{array}{l}\text { Receptive and expressive } \\
\text { language regarding } \\
\text { structure and content; } \\
\text { Pragmatic use of the } \\
\text { language }\end{array}$ & $\begin{array}{l}\text { Guillemin, Bombardier, } \\
\text { and Beaton }{ }^{15} \text {; Herdman, } \\
\text { Fox-Rushby, and Badia }{ }^{16} \text {; } \\
\text { Beaton, Bombardier, } \\
\text { Guillemin, Marcos }{ }^{10} ; \\
\text { Wang, Lee, and Fetzer }^{19} \text {; } \\
\text { Reichenheim and } \\
\text { Moraes }^{11} \text {; Gjersing, } \\
\text { Caplehorn, and Clausen }^{20} \\
\end{array}$ \\
\hline $\begin{array}{c}\text { Clinical Evaluation of } \\
\text { Language Functions - } \\
\text { 4th edition }\end{array}$ & $\begin{array}{l}\text { Wing, Second, } \\
\text { and Semel|21 }\end{array}$ & $\begin{array}{l}\text { Bento-Gaz and } \\
\text { Befi-Lopes }^{22}\end{array}$ & 5 to 21 years & $\begin{array}{l}\text { Receptive and expressive } \\
\text { language regarding } \\
\text { structure and content; } \\
\text { Pragmatic skills; } \\
\text { Cognitive and metacognitive } \\
\text { skills: working memory, } \\
\text { rapid and automatic } \\
\text { naming, phonological } \\
\text { awareness }\end{array}$ & $\begin{array}{l}\text { Guillemin, Bombardier, and } \\
\text { Beaton }^{15}\end{array}$ \\
\hline $\begin{array}{c}\text { Children's } \\
\text { Communication } \\
\text { Checklist-2 }\end{array}$ & $\begin{array}{l}\text { Bishop, } \\
\text { Maybery, } \\
\text { Wong, Maley, } \\
\text { Hallmayer }^{23}\end{array}$ & $\begin{array}{l}\text { Costa, Harsáyi, } \\
\text { Martins-Reis, } \\
\text { Kummer }{ }^{24}\end{array}$ & 4 to 16 years & $\begin{array}{l}\text { Pragmatic use of the } \\
\text { language; } \\
\text { Structural and content } \\
\text { aspects of the language; } \\
\text { Non-linguistic aspects: } \\
\text { Social relations and } \\
\text { interests }\end{array}$ & $\begin{array}{l}\text { International Society for } \\
\text { Pharmacoeconomics } \\
\text { and Outcomes Research } \\
\text { (ISPOR) } \\
\text { Wild, Grove, Martin, } \\
\text { Eremenco, McElroy, } \\
\text { Verjee-Lorenz et al. }{ }^{25}\end{array}$ \\
\hline $\begin{array}{l}\text { Parental Inventory } \\
\text { "Language Use } \\
\text { Inventory" }\end{array}$ & O'Neill|26 & $\begin{array}{l}\text { Brocchi, Osborn, } \\
\text { and Perissinoto } 27\end{array}$ & $\begin{array}{l}18 \text { to } 47 \\
\text { months }\end{array}$ & $\begin{array}{l}\text { Use of language - } \\
\text { pragmatics }\end{array}$ & $\begin{array}{c}\text { Herdman, Fox-Rushby, } \\
\text { and Badia }{ }^{16} \text {; Beaton, } \\
\text { Bombardier, Guillemin, } \\
\text { Marcos }^{10}\end{array}$ \\
\hline $\begin{array}{l}\text { Test of narrative } \\
\text { language (TNL) }\end{array}$ & $\begin{array}{l}\text { Gillam and } \\
\text { Pearson }^{28}\end{array}$ & $\begin{array}{l}\text { Rossi, Lindau, } \\
\text { Gillam, Giacheti } \\
{ }_{29}\end{array}$ & 5 to 11 years & $\begin{array}{l}\text { Narrative language: } \\
\text { Narrative comprehension } \\
\text { and oral narrative } \\
\text { production }\end{array}$ & $\begin{array}{c}\text { Gjersing, Caplehorn } \\
\text { and Clausen } n^{20} \text {; Borsa, } \\
\text { Damásio, and Bandeira }{ }^{30}\end{array}$ \\
\hline $\begin{array}{c}\text { Test de Sintaxis de } \\
\text { Aguado }\end{array}$ & Aguado ${ }^{31}$ & $\begin{array}{c}\text { Baggio and } \\
\text { Hage }^{5}\end{array}$ & 3 to 7 years & $\begin{array}{l}\text { Syntactic development - } \\
\text { expression and reception }\end{array}$ & $\begin{array}{l}\text { Beaton, Bombardier, } \\
\text { Guillemin, Marcos }\end{array}$ \\
\hline $\begin{array}{l}\text { Dynamic Evaluation of } \\
\text { Motor Speech Skills } \\
\text { (DEMSS) }\end{array}$ & \begin{tabular}{|c|} 
Strand, \\
McCauley, \\
Weigand, \\
Stoeckel, Baas ${ }^{32}$ \\
\end{tabular} & $\begin{array}{l}\text { Keske-Soares, } \\
\text { Uberti, Gubiani, } \\
\text { Gubiani, Ceron, } \\
\text { Pagliari }{ }^{33}\end{array}$ & $\begin{array}{c}3 \text { to } 6 \text { and a } \\
\text { half years }\end{array}$ & Speech sound production & Coster and Mancini34 \\
\hline
\end{tabular}

standardized assessment of expression and comprehension. It includes the non-standardized assessment of pragmatic aspects of the language and behaviors that might hinder interaction. The differential in PLAl- $2^{17}$ is the possibility to compare the receptive and expressive discourse skills and the presence of behaviors that might interfere with effective communication. Although
PLAIN-2 offers the comparison between language comprehension and expression and the verification of its pragmatics, it does not individually examine the linguistic subsystems. Therefore, it cannot be verified whether the language change is specifically related to mastering the language phonemes, syntax, or semantic relationships. 
The Clinical Evaluation of Language Functions $(C E L F)^{21}$, both in its $4^{\text {th }}$ and $5^{\text {th }}$ edition, was pointed out along with other instruments as having the best psychometric quality evidence of all the language assessments available in the market, being indicated to diagnose language disorders in childhood and adolescence ${ }^{36}$. The $4^{\text {th }}$ edition was the one adapted to Brazilian Portuguese ${ }^{22}$. The CELF-4 assesses various linguistic aspects regarding the form (phonology and syntax) and content (semantics), besides certain cognitive and communication skills considering the context (pragmatics). The performance in each of the tests can be obtained separately, which identifies what aspects of language are most affected - hence, this procedure is more refined than those described before. It also had tests that investigate skills underlying language processing, such as phonological awareness, automatic lexical access, short-term memory, and working memory. The instrument compares whether there is a discrepancy between receptive and expressive language and between language content and memory - which are essential data to a differential diagnosis of language change and to the therapeutic process. The procedure also provides a pragmatic profile of those assessed. All these characteristics make CELF one of the best language tests currently available ${ }^{36}$.

Unlike the previous ones, the Children's Communication Checklist-2 (CCC-2) ${ }^{23}$ and the Language Use Inventory (LUI) ${ }^{26}$ are not administered directly to the children but to the parents or caregiver. These instruments are categorized as parent reports, which have been greatly valued in the last years considering that parents are good evaluators of the children's everyday communication, as they are the ones who interact with them for longer. The CCC- ${ }^{23}$ has questions that verify children's and adolescents' possible difficulties communicating, as well as their strengths when communicating with other people. The questions that address caregivers are related to language form and content (syntax, semantics, and coherence), although there are also questions on the child's pragmatic use of the language, social relationships, and interests. The $\mathrm{LU}^{26}$ is a questionnaire that investigates specifically the pragmatic development of preschoolers 18 to 47 months old. It has questions on the child's communication in a range of communicative functions and daily activities. The questions involve information on how the child communicates with gestures, whether they ask for things, whether they adjust their talk to the context, whether they ask questions, make comments, or tell stories, besides other questionings. Both the CCC-223 and the $\mathrm{LUI}^{26}$ seek to identify children with pragmatic language disorders and are assessment instruments widely used to identify autism spectrum disorder ${ }^{37}$.

The Test of Narrative Language (TNL) ${ }^{28}$ and the Test de Sintaxis de Aguado (TSA) ${ }^{31}$ are administered directly to the children, but they are specific, that is, they evaluate a specific language skill (respectively, the narrative and the syntax) with the traditional analysis of the receptive (comprehension) and expressive (verbal production) aspects. The $\mathrm{TNL}^{28}$ is used to verify the preschoolers' and schoolchildren's performance in tasks of narrative comprehension and story production. Narrative comprehension is assessed with questions asked after telling a story, and the production is verified based on spontaneous narrative supported with images, which analyzes macrostructural aspects (such as the number of events, temporal relationship, conclusion, coherence) and microstructural aspects (such as vocabulary and grammar). The TSA ${ }^{31}$, in its turn, is an instrument that verifies syntactic aspects of language in children 3 to 7 years old. The test analyzes the children's morphosyntactic signal acquisition sequence, enabling the diagnosis of syntactic delays and disorders and furnishing information for intervention. Both the $\mathrm{TSA}^{31}$ and the $\mathrm{TNL}^{28}$ analyze one aspect of language, not diagnosing alone language disorders, despite making in-depth analyses.

The Dynamic Evaluation of Motor Speech Skills (DEMSS) $^{32}$ has a rather different objective from the other ones, as it assesses children with significant speech impairments, especially those with a small phonetic inventory, vowel or prosodic errors, little intelligible speech, or scarce/no verbal communication. The instrument helps in the differential diagnosis of preschoolers' speech sound disorders, which occur in cases of childhood apraxia of speech. With the DEMSS, the child is tested in the production of 60 statements, divided into eight sets organized according to the syllabic structure. The score considers the general word production precision, vowel precision, production consistency, and the word's prosodic resource precision.

It is important to highlight that, even though the eight instruments have been translated and adapted into Portuguese, they are not yet available in the market. The likely reason is that in addition to adaptation, other characteristics are necessary for a test to be used e.g., validity, reliability, and standardization. This shows 
that using an instrument in another language is a tough task because of its countless peculiar requirements. Translating and culturally adapting it is the first step, which must have very well-defined guidelines.

Considering now the guidelines, four ${ }^{14,18,27,29}$ of the eight articles included in this review used more than one set of guidelines - one article ${ }^{18}$ even mentioned six of them. Altogether, eight guidelines were mentioned, of which the most employed were those by Guillemin et. al ${ }^{15}$, Beaton et. $\mathrm{al}^{10}$, and Herdman et. $\mathrm{al}^{16}$.

The guidelines proposed by Guillemin, Bombardier, and Beaton ${ }^{15}$ were used in three translation and adaptation papers ${ }^{14,18,22}$, encompassing five stages: (1) translation; (2) back-translation; (3) reviewing committee; (4) pretest; (5) score weight adaptation to the cultural context. In the first stage, the content of the original text is translated into the target language. In it, the cross-cultural adaptation involves a combination of the literal translation of words and sentences from one language to the other and the adjustment to the cultural context and habits of the public to whom the translation is being made. Hence, in this stage, the translators not only express literally the content of the text but also adapt the translation to the target culture. Specific marks of the original culture need to be replaced with equivalent marks of the culture to whom it is being developed. This last aspect is crucial to language, speech, and communication tests, which must approach the social characteristics of the population who uses it. If a language or speech test is meant to identify possible disorders, the instrument must be adapted to what is used by the linguistic community. Furthermore, in stage one, the authors suggest that at least two independent translations be made to detect errors and interpretation differences. They also point out that the translators be preferably native and that at least one of them master the translated content. In the second stage, that of back-translation, the text is translated back into the original language. This is done to compare the original text with the version made in that same language to detect possibly inadequate meanings that may have resulted from the translation stage. They indicate that, in this stage, the same number of backtranslations be made as there were translations, and that none of the professionals be aware of the purpose of the text that is being back-translated to ensure that they will not be influenced by information from the translation context.

In the third stage, that of the reviewing committee, translators meet with an expert to evaluate the equivalences and technical terminology and change items that may not have been properly adapted. In the pretest stage, the instrument is administered to verify whether it is ready for use or some content needs to be changed for it to be better understood. However, this stage is not meant for any psychometric validation. In the last stage they proposed, the instrument's score weights must be adapted to the target culture, as they may not have the same value in its translated version.

The guidelines by Beaton et al. $^{10}$, used in three adaptations ${ }^{5,18,27}$, are a reformulation of those by Guillemin et al. ${ }^{15}$ - i.e., a stage is added to it, in which the translations are synthesized, and the "adaptation of score weights to the cultural context" is replaced with "submission of the documentation to the authors of the instrument". Hence, they are configured as follows: (1) translation; (2) synthesis of the translations; (3) backtranslation; (4) revision committee; (5) pretest; (6) submission of the documentation to the authors of the instrument or a follow-up committee. The translation synthesis stage requires that the translators of stage one meet to evaluate the differences found between the translations, creating a synthesized version. After the synthesis, the text is back-translated, having already been analyzed based on the discussions of the different interpretations of the translators. The stage in which the score weights are adapted to the cultural context has been replaced with the submission of documentation to the authors of the instrument as a means to control the various stages and how they were carried out.

When translating language instruments for children, it is crucial to carry out a pilot study - i.e., to administer the translated instrument to the target audience. The purpose is to make adjustments, as the results of the proposal are seen in practical terms. Having a follow-up committee of specialists also ensures further reliability to the translation process, as the knowledge of professionals in the field may substantially contribute to refining the translated instrument.

Both guidelines proposed by this group of researchers include recommendations to reach four levels of equivalence between the original text and the translation: (1) the semantic, aiming to avoid grammar and double-meaning difficulties; (2) the idiomatic, which is the use of colloquial language with equivalent expressions; (3) the experiential, which verifies whether the situations experienced in the instrument's original culture apply to the target culture; (4) the conceptual, which deals with the validity of the concept approached and the experiences in different cultures, as a given 
word may be semantically equivalent but still not convey the same meaning in different societies. These recommendations are essential for the translated word or sentence to convey the proper meaning in the language and culture of the target population. The translation and cultural adaptation of the TSA ${ }^{5}$ into Portuguese had to change the verb tenses in many sentences to ensure equivalence.

The guidelines by Herdman et al. ${ }^{16}$, like those by Guillemin et al. ${ }^{15}$ and Beaton et al. ${ }^{10}$, were cited in three ${ }^{14,18,27}$ of the eight reviewed translations, always in combination with one of them. These guidelines are based on the analysis of different types of equivalence: (1) conceptual equivalence, which appreciates whether the concepts and dimensions apprehended by the original instrument are appropriate to the target culture of the new version; (2) item equivalence, which analyzes whether the domains of the original instrument are relevant to the context of the culture that will use the translated text; (3) semantic equivalence, which verifies the meaning of the terms; (4) operational equivalence, which verifies the adjustment of the operational aspects in the new culture - form of administration, number of answer options; (5) measurement equivalence, which evaluates the correspondence between the psychometric properties of the original instrument and those of its new version; (6) functional equivalence, which confirms whether the instrument performs the task it is meant to. Only after checking the various equivalence aspects, it can be stated that the cross-cultural adaptation was indeed carried out ${ }^{16}$.

The guidelines by Reichenheim and Moraes ${ }^{11}$, cited in one of the articles ${ }^{18}$, were adapted from those by Herdman, Fox-Rushby, and Badia ${ }^{16}$, following the same stages but intended for use in epidemiologic studies.

The recommendations proposed by the International Society for Pharmacoeconomics and Outcomes Research (ISPOR $)^{25}$, which were used to adapt the CCC-2, have 10 steps: (1) preparation; (2) forward translation; (3) reconciliation; (4) back-translation; (5) back-translation review; (6) harmonization; (7) cognitive debriefing; (8) review of cognitive debriefing results and finalization; (9) proofreading; and (10) final report. Like the previously mentioned guidelines, those by ISPOR also suggest that at least two translations be made, which must be unified in the reconciliation stage - this is equivalent to the translation synthesis proposed by Beaton et al. ${ }^{10}$. Some differences are perceived - for instance, that the back-translation must be made by native professionals. The cognitive debriefing is the analysis of the comprehension levels, followed by the review of the results of this meeting to improve the performance of the translation.

The guidelines by Gjersing, Caplehorn, and Clausen ${ }^{20}$ were cited by two translation groups ${ }^{18,29}$. They suggest that the translation process be carried out with the following steps: (1) investigation of conceptual and item equivalence; (2) translation; (3) synthesis of translations; (4) back-translation; (5) synthesis of back-translations; (6) expert committee; (7) instrument pretest; (8) review of the instrument; (9) investigation of the operational equivalence; (10) instrument test; (11) exploratory and confirmatory analysis; (12) final version of the instrument. The first stage, that of conceptual and item equivalence, takes place before even beginning the translation process, which makes these guidelines different from the other ones. It aims to evaluate whether the fundamental concepts of the instrument in the original language are related to those in the target language. The guidelines by Gjersing et al. ${ }^{20}$ also recommend that at least two independent translations be made and that the professionals doing them be fluent in the target language and have a good understanding of the original language. Moreover, these translations should be synthesized into another version by a third professional, who must have the same competency as those who carried out the previous stage. Concerning the back-translations, the authors recommend that at least two be made independently by professionals who are fluent in the original language and have a good understanding of the target one. Besides the conceptual and item equivalence, already observed before beginning the translation process, operational and semantic equivalence are also approached in stage nine. These guidelines already envisage the instrument validation study carried out in stage eleven.

The guidelines by Borsa, Damásio, and Bandeira ${ }^{30}$ are cited in one article ${ }^{29}$. They suggest that the translation and cross-cultural adaptation process be made in six steps, namely: (1) translations; (2) synthesis of the translated versions; (3) evaluation of the synthesis by expert judges; (4) assessment of the instrument; (5) back-translation; and (6) pilot study. The authors' suggestions concerning the translation stage are that at least two independent nonliteral translations be made by bilingual professionals. It is further recommended that semantic, idiomatic, experiential, and conceptual equivalence be verified in the synthesis stage, with statistical analysis to verify to what extent the instrument 
can actually be considered valid for the context to which it was adapted.

Wang, Lee, and Fetzer ${ }^{19}$, which are also cited in one article ${ }^{18}$, suggest that the translation process be carried out in the following five steps: (1) translation, (2) revision, (3) back-translation, (4) equivalence test, and (5) reliability test. The differential aspects of these guidelines are in their proposal of working with bilingual translators and having a translation equivalence test, in which the instrument is tested in two groups, one with monolingual and the other, bilingual speakers.

The DEMMS ${ }^{32}$ was adapted with the guidelines by Coster and Mancini ${ }^{34}$, which are compatible with the previous ones, with a few differences. Their steps are (1) ensuring permission; (2) translation; (3) backtranslation; (4) development of the final version; (5) evaluation of the translated instrument. The authors recommend that at least two independent translations be made, either by two people or two teams. Regarding the professionals to be chosen for the translation, the authors say they must be fluent in both languages and familiarized with the instrument and the context to which it was developed. They further suggest in this stage that the translations previously made be mingled into one by a third person, whom they name as process coordinator - this stage is also suggested in other guidelines, though as a separate stage instead of part of the translation stage. For the back-translation stage, as in the previous one, it is suggested that they be made by two different people or teams, which must not have contact with each other. If they do not agree concerning a possible difference, a bilingual professional must be consulted. The authors also recommend another two steps, namely: administering the instrument to a group of potential users (to find items whose meaning is not clear or fluent to those who will use it) and submitting it to the cognitive test (in which the instrument is administered to target subjects to evaluate whether the items were understood as expected).

Four ${ }^{5,18,24,29}$ of the eight reviewed articles counted with professionals for the translation process. It sounds advisable to decide for professional translators, as translating is not simply a linguistic task, but a combination of textual, communicative, and cognitive activities, in which the functioning of the texts must be considered, as well as their relationship with the context and mental processes involved ${ }^{38}$. Thus, a professional translator has the competency acquired during their training process, which encompasses bilingual and extralinguistic sub-competencies and knowledge of instrumental and strategic translation ${ }^{38}$.

The bilingual sub-competency refers to the knowledge necessary to communicate between two languages - e.g., pragmatic, textual, lexical, and sociolinguistic knowledge. The extralinguistic one is the knowledge of both cultures. The knowledge of translation, in its turn, approaches the information that guides the translation, as translation units, methods, and procedures. The instrumental deals with knowledge of the documentation source and the technologies related to translation. And the strategic approaches the operational knowledge necessary to ensure the effectiveness of the translation, which involves planning and evaluating the whole process, choosing the method to be used, identifying the translation problems, and using the procedures and strategies to solve and activate the other sub-competencies ${ }^{38}$.

Research conducted with groups of professional translators and bilingual subjects with no translation experience, using the dynamic index of knowledge of translation ${ }^{39}$, verified that the professional translators tend to have a more dynamic view of the translation process, considering aspects such as the function of the text and the culture, while the bilingual subjects have a static view of the translation ${ }^{40}$, understanding it as a linguistic activity that requires literality. Hence, in the process of translating language, speech, or communication tests, the speech-language-hearing therapist - who knows the specificities, the specific vocabulary, and the clinical experiences approached in the instrument - and the professional translator must cooperate to achieve optimal results in translations and cross-cultural adaptations of instruments whose objective is to identify communication disorders.

\section{CONCLUSIONS}

The review pointed out eight instruments translated and adapted into Brazilian Portuguese to assess expressive and receptive language, communicative skills, and speech sounds of children under 10 years old. Three aimed at specific investigations, such as syntax, narrative, and pragmatic skills. Likewise, only one article was found to verify the organization of speech sounds - which indicates a scarcity in this field. Another four have a more encompassing profile, as they assess the form, content, and/or use (pragmatics). Two out of the eight procedures are administered to the parents, considering that those who take care of the children can be good assessors of their everyday 
communication. There are still few instruments translated and adapted into Brazilian Portuguese to assess the children's language and sound speech production, as compared with the number of existing procedures in English.

Concerning the guidelines, the following were the most recurrent stages between the translation proposals: having the translation and back-translation made by two different translators with a synthesis version in both stages; forming a committee with the translator and a specialist in the field; administering the instrument in a pilot study; producing a final version. The conceptual, item and operational equivalences were the most cited for verification. The most recurrent guidelines were those by Guillemin et al. ${ }^{15}$ and Beaton et al. $^{10}$, both from the same workgroup, and by Herdman et al. ${ }^{16}$, whose difference from the other two is that it verifies various types of equivalence.

The participation of translators in the translation and cross-cultural adaptation process was verified in four papers, indicating an optimistic perspective regarding the interdisciplinarity between the fields of speechlanguage-hearing sciences and translation to achieve the best possible results.

\section{REFERENCES}

1. Ferreira $A B H$, editor. Dicionário Aurélio da Língua Portuguesa. 5. ed. Curitiba: Positivo; 2010.

2. American Speech-Language-Hearing Association. ASHA. USA, c1997-2019.

3. Giusti E, Befi-Lopes DM. Tradução e adaptação transcultural de instrumentos estrangeiros para o Português Brasileiro (PB). Pró-Fono R Atual Cient. 2008;20(3):207-10.

4. Lindau TA, Lucchesi FDM, Rossi NF, Giacheti CM. Systematic and formal instruments for language assessment of preschoolers in Brazil: a literature review. Rev. CEFAC. 2015;17(2):656-62.

5. Baggio GI, Hage SRV. Translation and cultural adaptation of the Aguado Syntax Test (AST) into Brazilian Portuguese. CoDAS. 2017;29(6):e20170052.

6. Ferreira-Vasques AT, Santos CF, Lamônica DAC. Transcultural adaptation process of the Griffiths-III Mental Development Scale. Child Care Health Dev. 2019;45(3):403-8.

7. Silva NR, Felipini LMG. Tradução e adaptação transcultural de instrumentos de avaliação em Fonoaudiologia para o português brasileiro: uma análise das diretrizes. Tradterm. 2018;32:32-51.
8. Andrade CRF, Juste F. Proposta de análise de performance e de evolução em crianças com gagueira desenvolvimental. Rev. CEFAC. 2005;7(2):158-70.

9. Pernambuco L, Espelt A, Magalhães Junior HV, Lima KC. Recommendations for elaboration, transcultural adaptation and validation process of tests in Speech, Hearing and Language Pathology. CoDAS. 2017;29(3):e20160217.

10. Beaton DE, Bombardier C, Guillemin F, Marcos MB. Guidelines for the process of cross-cultural adaptation of self-report measures. Spine. 2000;25(24):3186-91.

11. Reichenheim ME, Moraes CL. Operationalizing the cross-cultural adaptation of epidemiological measurement instruments. Rev Saúde Pública. 2007;41(4):665-73.

12. Nascimento E, Figueiredo VLM. WISC-III e WAIS-III: alterações nas versões originais americanas decorrentes das adaptações para uso no Brasil. Psicologia: Reflexão e Crítica. 2002;15(3):603-12.

13. Hresko WP, Reid KD, Hammill DD. TELD 3 Test of Early Language Development Third Edition. 3th edition. Austin, TX: Pro-ed; 1999.

14. Giusti E, Befi-Lopes DM. Performance de sujeitos falantes do Português e do Inglês no Test of Early Language Development. Pró-Fono R. Atual. Cientif. 2008;20(1):13-8.

15. Guillemin F, Bombardier C, Beaton D. Cross-cultural adaptation of health-related quality of life measures: literature review and proposed guidelines. J Clin Epidemiol. 1993;46(12):1417-32.

16. Herdman M, Fox-Rushby J, Badia X. A model of equivalence in the cultural adaptation of HRQol Instruments: the universalist approach. Qual Life Res. 1998;7(4):323-35.

17. Blank M, Rose SA, Berlin LJ. Preschool Language Assessment Instrument. 2nd edition. Austin: Pro-ed; 2003.

18. Lindau TA, Rossi NF, Giacheti CM. Crosscultural adaptation of Preschool Language Assessment Instrument: second edition. CoDAS. 2014;26(6):428-33.

19. Wang WL, Lee HL, Fetzer SJ. Challenges and strategies of instrument translation. West $\mathrm{J}$ Nurs Res. 2006;28(3):310-21.

20. Gjersing L, Caplehorn J, Clausen T. Cross-cultural adaptation of research instruments: language, setting, time and statistical considerations. BMC Med Res Methodol. 2010;10(1):1471-2288. 
21. Wing EH, Second WA, Semel E. Evaluation of Language Function (CELF-4). 4th edition. San Antonio: Pearson; 2003.

22. Bento-Gaz ACP, Befi-Lopes DM. Adaptation of Clinical Evaluation of Language Functions - 4th Edition to Brazilian Portuguese. CoDAS. 2014;26(2):131-7.

23. Bishop DVM, Maybery M, Wong D, Maley A, Hallmayer J. Characteristics of the broader phenotype in Autism: a study of siblings using the Children's Communication Checklist-2. Am J Med Genet B Neuropsychiatr Genet. 2006;141B(2):117-22.

24. Costa VBS, Harsáyi E, Martins-Reis VO, Kummer A. Translation and cross-cultural adaptation into Brazilian Portuguese of the Children's Communication Checklist-2. CoDAS. 2013;25(10):115-9.

25. Wild D, Grove A, Martin M, Eremenco S, McElroy $S$, Verjee-Lorenz A et al. Principles of good practice for the translation and cultural adaptation process for patient-reported outcomes (PRO) measures: report of the ISPOR Task Force for translation and cultural adaptation. Value Health. 2005;8(2):94-104.

26. O'Neill DK. The Language Use Inventory for Young Children: a parent-report measure of pragmatic language development for 18- to 47-month-old children. J. Speech Lang. Hear. Res. 2007;50(1):214-28.

27. Brocchi BS, Osborn E, Perissinoto J. Translation of the Parental Inventory "Language Use Inventory" into Brazilian Portuguese. CoDAS. 2019;31(2):e20180129.

28. Gillam R, Pearson N. Test of Narrative Language: examiner's manual. Rio de Janeiro: Pro-ed; 2004.

29. Rossi NF, Lindau TA, Gillam RB, Giacheti CM. Cultural adaptation of the Test of Narrative Language (TNL) into Brazilian Portuguese. CoDAS. 2016;28(5):507-16.

30. Borsa JC, Damásio BF, Bandeira DR. Adaptação e validação de instrumentos psicológicos entre culturas: algumas considerações. Paidéia. 2012;22(53):423-32.

31. Aguado G. El desarrollo de la morfosintaxis en el niño: manual de evaluación del TSA. Madrid: CEPE; 1989.
32. Strand EA, McCauley RJ, Weigand SD, Stoeckel RE, Baas BS. A motor speech assessment for children with severe speech disorders: reliability and validity evidence. J Speech Lang Hear Res. 2013;56(2):505-20.

33. Keske-Soares M, Uberti LB, Gubiani MB, Ceron MI, Pagliarin KC. Performance of children with speech sound disorders in the dynamic evaluation of motor speech skills. CoDAS. 2018;30(2):e20170037.

34. Coster WJ, Mancini MC. Recomendações para a tradução e adaptação transcultural de instrumentos para a pesquisa e a prática em Terapia Ocupacional. Rev Ter Ocup Univ São Paulo. 2015;26(1):50-7.

35. Bloom L. What is language? In: Lahey $M$, editor. Language disorders and language development. New York: Macmillian Publishing Company; 1988. p. 1-19.

36. Denman D, Speyer R, Munro N, Pearce WM, Chen YW, Cordier R. Psychometric properties of language assessments for children aged 4-12 years: a systematic review. Front Psychol. 2017;8:1515.

37. Charman T, Baird G, Simonoff E, Loucas T, Chandler S, Meldrum $D$ et al. Efficacy of three screening instruments in the identification of autistic-spectrum disorders. $\mathrm{Br} J$ Psychiatry. 2007;191(6):554-9.

38. Hurtado AA. A aquisição da competência tradutória: aspectos teóricos e didáticos. In: Pagano A, Magalhães $C$, Alves $F$, editors. Competência em tradução: cognição e discurso. Belo Horizonte: Editora UFMG, 2005. p. 19-57.

39. Bebby A, Fernández M, Fox O, Hurtado AA, Kozlova I, Kuznik A et al. First results of a translation competence experiment: 'Knowledge of Translation' and 'Efficacy of the Translation Process'. In: Kearns $\mathrm{J}$, editor. Translator and interpreter training: issues, methods and debates. London: Continuum International Publishing Group, 2008. p. 104-26.

40. Bebby A, Fernández MR, Fox $O$, Hurtado AA, Neuzig $\mathrm{W}$, Orozco $\mathrm{M}$ et al. Building a translation competence model. In: Alves $F$, editor. Triangulating translation: perspectives in process oriented research. Amsterdam; Philadelphia: John Benjamins, 2003. p. 43-66. 